\title{
Prevalence and associated factors of congenital anomalies in a tertiary care centre in Tamilnadu
}

\author{
Prema $N^{1}$, Sudhakaran $R^{2}$, Divya. B. $V^{3}$, Meerabai $V^{4}$, Maharani ${ }^{5}$ \\ ${ }^{1}$ Dr. Prema. N, Assistant Professor, Department of Obstetrics and Gynaecology, ${ }^{2}$ Dr. Sudhakaran. R, Assistant Professor, \\ Department of Anaesthesia, ${ }^{3}$ Dr. Divya. B.V., Assistant Professor, Department of Community Medicine, ${ }^{4}$ Dr. Meerabai V., \\ Professor, Department of Obstetrics and Gynaecology, ${ }^{5}$ Dr. Maharani, Professor, Department of Obstetrics and Gynaecology, \\ all authors are affiliated with Karpagam Faculty of Medical Sciences and Research, Coimbatore, Tamilnadu, India.
}

Address for Correspondence: Dr. Prema. N, 105, A- Block, Staff Quarters, Karpagam Faculty of Medical Sciences And Research, Othakkalmandapam, Coimbatore, Tamilnadu, India. Email: drnprema@gmail.com.

\begin{abstract}
Background: A birth defect or congenital anomaly is an abnormality of structure, function or body metabolism that is present at birth and results in physical or mental disability. Evaluation and management of newborns with one or more malformations present a significant challenge to the healthcare providers and families. Despite major advances in understanding the etiology and pathogenesis, malformations remain a leading cause of infant mortality. This study brings about the prevalence of congenital anomalies among antenatal patients delivering beyond the period of viability, 22 weeks in a tertiary care centre in Tamilnadu and also the pattern of anomalies, along with the associated factors. Materials and Methods: A cross sectional study with nested case control design was conducted in a tertiary care centre in Taminadu for one year from July 2015 to June 2016. Those fetuses induced in second trimester following detection by ultrasound and those babies detected to have congenital anomalies by postnatal examination were included in the study. Data of 191 cases and 191 controls were collected by interviewing the mothers and reviewing the existing patient records. Relevant antenatal, natal, postnatal and past illnesses were recorded in a proforma and analysed. Results: In the study period, 191 babies out of 9877 were anomalous with a prevalence of $1.93 \%$. Anomalies of the central nervous system were the commonest (35.6\%). The ultrasound detection rate was $67.01 \%$. Maternal age $>25$ years was seen in $55 \%$. About $15.7 \%$ of the mothers had consanguineous marriage. The distribution among primigravida and multipara are almost similar.16.2\% of cases had a history of infertility in the mother. $8.4 \%$ of the cases had a family history. About $4.7 \%$ cases had a history of exposure to antiepileptic drugs. Maternal diabetes mellitus and epilepsy contributed $32.5 \%$ and $4.5 \%$ of cases respectively. Intrauterine growth restriction and amniotic fluid abnormalities were commonly associated. Conclusion: The study helps to know the pattern of congenital anomalies and the relationship of various gestational and familial factors and the importance of ultrasound in diagnosing anomalies. Surveillance of anomalies should be a must and all maternity hospitals should have their own anomaly register. Parents of any surviving anomalous child should receive emotional support and reassurance.
\end{abstract}

Key words: Congenital Anomaly, Consanguinity, Diabetes Mellitus, Neural Tube Defect

\section{Introduction}

Evaluation and management of newborns with one or more malformations present a significant challenge to healthcare providers and families. Despite major advances in understanding the etiology and pathogenesis, malformations remain a leading cause of infant mortality [1]. These children become an emotional burden to their families. A birth defect or a congenital anomaly is an abnormality of structure, function or body metabolism that is present at birth and results in physical or mental

Manuscript received: $8^{\text {th }}$ December 2016

Reviewed: $16^{\text {th }}$ December 2016

Author Corrected: $24^{\text {th }}$ December 2016

Accepted for Publication: $31^{\text {st }}$ December 2016

Obsgyne Review: Journal of Obstetrics and Gynecology disability or is fatal [2]. There are more than 4000 known birth defects. Major congenital abnormality is defined as those defects which cause serious structural, cosmetic and functional disability requiring surgical or medical management. Minor congenital abnormality may be defined as unusual morphologic features that are of no serious medical or cosmetic consequences [3].

Further classification of physical defects includes malformation, deformation, disruption, dysplasia, sequence, syndrome and association [3]. Any congenital anomaly must be described in terms of nomenclature. Considerable variation in frequency has been reported

Available online at: www.medresearch.in 55 | $\mathrm{P}$ a g e 
among different populations. Studies in India reveal an incidence of 3 to $4 \%$ [4]. In Japan the incidence has been reported to be $1.07 \%$ and in Taiwan it is $4.3 \%$. In spite of high frequencies of congenital anomalies, the cause remains obscure. Around 15 to $20 \%$ are due to recognized genetic conditions, 8 to $10 \%$ are due to environmental factors (maternal related conditions, drugs or chemical exposure) and 20 to $25 \%$ are due to multi factorial inheritance [5]. The majority 40 to $60 \%$ of congenital anomalies have unexplained causes [5].

Although minor birth defects are often correctable, the emotional and economic burden on the family and society is considerable and invariably leaves families and healthcare providers with unanswered questions regarding the causes, recurrent risks and preventive measures. Musculoskeletal malformations are the commonest in most of the Indian studies [6].

Ultrasound is an accurate method to diagnose malformations prenatally in high risk group of pregnant women [7]. However most anomalies are found among newborns from pregnancies without risk factors. Therefore an ultrasound is offered to all pregnant women with the aim of screening for fatal anomalies. The modalities, the reliability and the value of such a screening are controversial. Usually an anomaly scan is done at 18 to 20 weeks [7]. When one anomaly is detected it is imperative that other anomalies are sought for and confirmed or ruled out.

Antenatal diagnosis of abnormality allows parents not only the option of termination but also time to plan care for the child. Prenatal diagnosis of congenital anomalies provides information for decisions during pregnancy and appropriate treatment perinatally and it is assumed to improve perinatal and long term outcome.

Congenital malformations have always been an attraction for researchers because of the high frequency with which they occur and the devastating effects they have on the individual and the family.

Congenital anomalies account for a large fraction of childhood mortality and morbidity. Around the world lot of importance is being focused on congenital anomalies with a decline in the mortality from other causes like infectious diseases.

This study brings out the prevalence of congenital anomalies of antenatal patients delivering beyond the period of viability 22 weeks in a tertiary care centre in Tamilnadu and also the pattern of anomalies along with the associated factors.

\section{Materials and Methods}

Study design: Cross sectional study with nested case control design

Study setting: A tertiary care centre in Tamilnadu for a period of one year from July 2015 to June 2016

Study population: Antenatal patients admitted to the labour room, either booked or referred, delivering an anomalous baby (live/stillborn) beyond the period of viability was taken as the case. Next patient in the parturition register was taken as the control.

To study the maternal and fetal risk factors, total number of cases and controls would be 191 each.

\section{Inclusion criteria}

1. Congenitally anomalous babies beyond 22 weeks of gestation (live/stillborn) delivered in our hospital were taken for the study

2. An infant with more than one anomaly was counted only once

\section{Exclusion criteria}

1. Babies delivered out of our hospital admitted due to anomalies

2. Gestational age less than 22 weeks.

Methodology: A study was conducted in a tertiary care centre in Tamilnadu for a period of one year. Those fetuses induced in second trimester following detection by ultrasound and those babies detected to have congenital anomalies by postnatal examination were included in the study. Data was collected by interviewing the mothers and reviewing the existing patient records.

Relevant antenatal, natal, postnatal and past illnesses were recorded in a preplanned proforma. Details like maternal age, parity, family history, consanguinity, history of infertility, exposure to teratogens, medical history and pregnancy losses in the past were noted.

Details of ultrasound were noted. The babies were examined in the labour room with help from labour room paediatrician and anomalies noted and recorded.

Statistical analysis: The data was entered into masterchart and necessary statistical tables were constructed. In order to test hypothesis, statistical tests like Chi square test and odds ratio were used. 


\section{Results}

In the study period 191 babies out of 9877 were anomalous and this gives a prevalence of congenital anomalies in the antenatal patients delivering beyond the period of viability as $1.93 \%$.

Table-1: Pattern of anomalies noted.

\begin{tabular}{|c|c|c|}
\hline System & Count & Percentage \\
\hline Central nervous system & 68 & $35.6 \%$ \\
\hline Musculoskeletal system & 45 & $23.6 \%$ \\
\hline Genitourinary system & 36 & $18.8 \%$ \\
\hline Cardiovascular system & 10 & $5.2 \%$ \\
\hline Gastrointestinal system & 8 & $4.2 \%$ \\
\hline Syndromes & 8 & $4.2 \%$ \\
\hline Miscellaneous & 16 & $8.4 \%$ \\
\hline Total & $\mathbf{1 9 1}$ & $\mathbf{1 0 0}$ \\
\hline
\end{tabular}

Anomalies of the central nervous system were the commonest (35.6\%) followed by musculoskeletal system anomalies which was contributed by $23.6 \%$. Anomalies of the gastrointestinal system was least commonly noted in the study.

Table-2: Ultrasound detection rate of anomalies.

\begin{tabular}{|c|c|c|c|}
\hline System & Total cases & Cases detected by ultrasound & Percentage \\
\hline Central nervous system & 68 & 55 & $80.88 \%$ \\
\hline Musculoskeletal & 45 & 27 & $60 \%$ \\
\hline Genitourinary & 36 & 24 & $66.67 \%$ \\
\hline Cardiovascular & 10 & 6 & $60 \%$ \\
\hline Gastrointestinal & 8 & 4 & $50 \%$ \\
\hline Syndromes & 8 & 3 & $37.50 \%$ \\
\hline Miscellaneous & 16 & 9 & $56.25 \%$ \\
\hline
\end{tabular}

The ultrasound detection rate in total was $67.01 \%$. A total of 128 cases were detected sonologically of the 191 cases. Detection rate was $80.88 \%$ for central nervous system anomalies.

Table-3: Period of gestation of first detection of anomalies by ultrasound

\begin{tabular}{|c|c|c|c|}
\hline System & $<18$ Weeks & 18-20 Weeks & $>20$ Weeks \\
\hline Central nervous system & 2 & 4 & 49 \\
\hline Musculoskeletal & 12 & 0 & 15 \\
\hline Genitourinary & 0 & 10 & 14 \\
\hline Cardiovascular & 0 & 0 & 6 \\
\hline Gastrointestinal & 0 & 0 & 4 \\
\hline Syndromes & 0 & 0 & 3 \\
\hline Miscellaneous & 0 & 0 & 9 \\
\hline Total & $14(10.93 \%)$ & $14(10.93 \%)$ & $100(78.13 \%)$ \\
\hline
\end{tabular}

Although ultrasound picked up a fairly good number of anomalies, the period of gestation when it detected was beyond 20 weeks in majority of the cases. This rise is however spurious because the study included only cases delivered beyond the period of viability and probably lethal anomalies detected before 20 weeks had undergone termination of pregnancy earlier. Ultrasound detected 100 anomalous babies after 20 weeks and 63 cases were left undetected which could be minimized thus reducing perinatal morbidity. 
Table-4: Distribution of subjects- family history of anomaly.

\section{Original Research Article}

\begin{tabular}{|c|c|c|}
\hline Family history of anomaly & Cases & Controls \\
\hline Present & $16(8.4 \%)$ & $0(0 \%)$ \\
\hline Absent & $175(91.6 \% 0$ & $191(100 \%)$ \\
\hline Total & $\mathbf{1 9 1 ( 1 0 0 \% )}$ & $\mathbf{1 9 1 ( 1 0 0 \% )}$ \\
\hline
\end{tabular}

Increasing maternal age $>25$ years was seen in $55 \%$ of the cases while it was $44.5 \%$ among the controls and this difference was statistically significant to state an association between the increasing maternal age and anomalies in the fetus. Of the 191 cases $68.1 \%$ were referred while it was only $12.6 \%$ among the controls. Consanguinity was present in the mothers in $15.7 \%$ of the cases while it was $3.1 \%$ in the controls and consanguinity was more prevalent among Muslims, most of them being third degree.

History of infertility in the mother bears a significant association with congenital anomaly in the fetus. $8.4 \%$ of the cases had a family history of anomalies (first degree relatives) while none of the controls had such a history.

Table-5: Distribution of subjects-history of previous anomalous pregnancy.

\begin{tabular}{|c|c|c|}
\hline History of previous anomalous pregnancy & Cases & Controls \\
\hline Present & $12(6.3 \%)$ & $4(2.1 \%)$ \\
\hline Absent & $179(93.7 \%)$ & $187(97.9 \%)$ \\
\hline Total & $191(100 \%)$ & $191(100 \%)$ \\
\hline
\end{tabular}

Previous history of adverse pregnancy outcome in the mother in the form of miscarriage, intra uterine fetal demise, still birth and neonatal death was found to be a significant risk factor for congenital anomaly and was present in $24.1 \%$ of the cases and $9.4 \%$ of the controls. $6.3 \%$ of the cases and $2.1 \%$ of the controls had a maternal history of previous anomalous pregnancy and this difference was not statistically significant.

Table-6: Distribution of subjects-periconceptional folic acid intake.

\begin{tabular}{|c|c|c|}
\hline Periconceptional folic acid intake & Cases & Controls \\
\hline Present & $131(68.6 \%)$ & $71(37.2 \%)$ \\
\hline Absent & $60(31.4 \%)$ & $120(62.8 \%)$ \\
\hline Total & $\mathbf{1 9 1 ( 1 0 0 \% )}$ & $\mathbf{1 9 1 ( 1 0 0 \% )}$ \\
\hline
\end{tabular}

Maternal periconceptional folic acid was present in $31.4 \%$ of the cases while $62.8 \%$ of controls took periconceptional folicacid and hence the intake of periconceptional folic acid has a preventive role in congenital anomalies and the association between the two is statistically significant.

Table-7: Maternal diabetes

\begin{tabular}{|c|c|c|}
\hline Maternal diabetes & Cases & Controls \\
\hline Present & $62(32.5 \%)$ & $10(5.2 \%)$ \\
\hline Absent & $129(67.5 \%)$ & $181(94.8 \%)$ \\
\hline Total & $191(100 \%)$ & $191(100 \%)$ \\
\hline
\end{tabular}

Maternal fever in the first trimester was found in $7.9 \%$ of cases and $4.7 \%$ of controls. Statistically significant difference has been found between the cases and controls with regard to maternal intake of teratogenic drugs in the first trimester. $4.7 \%$ of the cases and $0.5 \%$ of the controls had the history which was mainly antiepileptic drugs. $32.5 \%$ of the cases had maternal diabetes both gestational and overt when compared to $5.2 \%$ of the controls and the difference observed has been found to be statistically significant. 
Table-8: Maternal epilepsy.

Original Research Article

\begin{tabular}{|c|c|c|}
\hline Maternal epilepsy & Cases & Controls \\
\hline Present & $9(4.7 \%)$ & $1(0.5 \%)$ \\
\hline Absent & $182(95.3 \%)$ & $\mathbf{1 9 1 ( 1 0 0 \% )}$ \\
\hline Total & $\mathbf{1 9 1 ( 1 0 0 \% )}$ & $(99.5 \%)$ \\
\hline
\end{tabular}

Maternal epilepsy complicated $4.7 \%$ of the cases and $0.5 \%$ of the controls and this difference when analysed was found to be statistically significant and thus epilepsy in the mother has a significant association with an anomalous fetus, in the study.

Table-9: Significant factors associated with congenital anomalies.

\begin{tabular}{|c|c|c|}
\hline Factor & Cases & Percentage \\
\hline Maternal age $>25$ yrs & 105 & 65.1 \\
\hline Referred & 130 & 15.7 \\
\hline Presence of consanguinity & 30 & 16.2 \\
\hline Presence of maternal history of infertility & 31 & 24.1 \\
\hline Presence of family history of anomaly & 16 & 68.6 \\
\hline Presence of maternal history of previous adverse pregnancy & 46 & 4.7 \\
\hline Absence of periconceptional folic acid & 131 & 32.5 \\
\hline Presence of drug intake in first trimester & 9 & 4.7 \\
\hline Presence of maternal diabetes & 62 & 27.2 \\
\hline Presence of maternal epilepsy & 9 & 60.7 \\
\hline Presence of maternal spotting PV & 52 & 22.5 \\
\hline Presence of IUGR & 116 & 31.9 \\
\hline Presence of oligamnios & 43 & 69.6 \\
\hline Presence of hydramnios & 61 & 133 \\
\hline
\end{tabular}

$27.2 \%$ of the cases had a history of spotting or bleeding per vaginum in the early trimester in the mother as compared to $5.2 \%$ of the controls making it a significant associated factor. $60.7 \%$ of the cases as against of $20.4 \%$ of the controls showed intra uterine growth restriction making the difference statistically significant thus implicating IUGR as an associated factor. $22.5 \%$ of the cases had oligamnios as compared to $5.2 \%$ of the controls. $31.9 \%$ of the cases and $1 \%$ of the controls showed hydramnios and when analysed this difference was found to be significant in the study defining an association between hydramnios and fetal anomalies. Of the 191 cases, $69.6 \%$ were male babies, $25.1 \%$ females and 5.2\% had ambiguous genitalia while in the controls $50.3 \%$ were males and $49.7 \%$ were females.

\section{Discussion}

This study reflects the results obtained from a tertiary care centre in Tamilnadu. This study has brought about the perinatal morbidity and mortality resulting from the birth of a viable anomalous baby.

Pattern of anomalies- Malformations of the central nervous system was the commonest in the present study accounting for about $35.6 \%$ of the total anomalies followed by musculoskeletal system $(23.6 \%)$, the genitourinary system, the cardiovascular system and the gastrointestinal system. In central nervous system anomalies, anencephaly was the commonest [7].

Central nervous and musculoskeletal system anomalies showed predominance over the rest in many of the studies conducted in india and abroad. Many studies show that central nervous system malformations were associated with very high perinatal mortality [8]. 


\section{Original Research Article}

Genitourinary anomalies ranked third with $18.8 \%$ of the total anomalies and hydronephrosis was the commonest genitourinary anomaly. This system was followed by the cardiovascular system and gastrointestinal system accounting for $5.2 \%$ and $4.2 \%$ of the total anomalies respectively.

A study conducted in the Banaras Hindu University, showed similar results. The central nervous system $(39.5 \%)$ was most commonly involved followed by musculoskeletal system (14.5\%) [9].

A hospital based study conducted in Jammu showed higher incidence of musculoskeletal anomalies. The pattern of congenital anomalies included musculoskeletal $(30.6 \%)$, central nervous system $(20.5 \%)$, gastrointestinal tract $(18.5 \%)$, genitourinary $(4.7 \%)$ and cardiovascular system (4\%) [10].

There were 8 cases of identifiable syndromes of which 5 cases were Downs syndrome and this may be attributed to increasing maternal age.

Ultrasound picked up $67.01 \%$ of the 191 cases. The detection rates were higher when serial scans were done in the second trimester. Ultrasound picked up $80.88 \%$ of central nervous system malformations, $60 \%$ of the musculoskeletal anomalies, $66.67 \%$ of genitourinary anomalies, $50 \%$ of gastrointestinal tract anomalies, $60 \%$ of cardiovascular system anomalies and $37.50 \%$ of syndromes. Chitty et al evaluated the effectiveness of routine ultrasound in unselected general population $[11,12]$. He observed that early anomaly scan brought down the perinatal mortality and morbidity significantly. Besides it saves a lot of anxiety for the couple and their family. Helsinski trial found that early ultrasound detection led to an increased rate of elective abortions and therefore reduced perinatal death [12]. On the other hand radius trial found no statistically significant effect on the rate of induced abortions.

\section{Risk factors associated with anomalies}

Maternal age- In the present study $55 \%$ of the cases were associated with a maternal age of more than 25 years while it was $44.5 \%$ for the controls. The mean maternal age in the control population was 24.31 years while it was 25.31 years for the cases, yet this small difference was found to be statistically significant defining an association between increasing maternal age and anomalous fetus.

Many authors have shown higher incidence of malformations in the babies born to mothers aged over 35 years[12,13], while others have associated 20-35 years maternal age group with higher incidence of congenital malformation[14,15].

Booking status- Majority of the cases $68.1 \%$ were referred while among the controls it was only $12.6 \%$. This might be due to the fact that many cases of congenital anomalies being referred to a tertiary care centre for a better neonatal care. This difference has been found to be statistically significant.

Religion-The religionwise distribution of both cases and the controls are similar and this is in contrast to certain studies which showed a preponderance of anomalies among Muslims due to consanguineous marriage [15]

Consanguinity-Third degree consanguineous marriage was present in 30 cases and 6 controls and difference being a statistically significant one $[14,15,16]$.

Kesavan $\mathrm{P}$ et al also found a similar relationship. He observed an increased incidence of congenital anomalies among the offsprings of consanguineous mating [16].

Parity-The distribution of study subjects according to parity was more or less similar in both the groups and was not statistically significant. Congenital anomalies were seen more frequently in mothers who had a parity of 4 and above. Chaturvedi et al recorded increase in frequency of central nervous system anomalies in primi and fourth gravida mothers [17].

Infertility-History of infertility was present in $16.2 \%$ of the cases and $4.2 \%$ of the controls the difference being statistically significant. This is accordance with Kovacis et al who found an increased predeliction for multiple pregnancies and congenital anomalies with infertility and assisted reproductive techniques [18].

Family history of anomalies- $8.4 \%$ of the cases had a family history of anomalies in the first degree relatives when compared to none among the controls

Previous adverse pregnancy outcome- $24.1 \%$ of the cases had a maternal history of previous adverse pregnancy outcome while $9.4 \%$ of the controls had a similar history. A study by Bhat BV in India reported significant relationship between positive history of previous abortion [19,20,21].

Previous anomalous pregnancy- $6.3 \%$ of the cases and $2.1 \%$ of the controls had a maternal history of previous anomalous pregnancy and this was not found to be statistically significant. 
Periconceptional folic acid- $62.8 \%$ of the controls had a maternal periconceptional folic acid intake when compared to $31.4 \%$ of the cases. Several studies show that ensuring maternal folic acid supplementation during the periconceptional period can lower the incidence of these anomalies [20,21]

Teratogen exposure in the first trimester- Among teratogens, drug intake in the mother was the only significant risk factor found to be associated with fetal anomalies in the present study. Febrile illness and radiation exposure were distributed equally among the cases and controls drawing no significance.

Study conducted by Menon VK and Bharucha KE concluded that environmental influences like drug, radiation exposure, substance abuse and febrile illness were not found to be responsible for the genesis of congenital anomalies[22,23,24].

Maternal illness- Maternal diabetes and epilepsy were found to have statistically significant association with fetal congenital anomalies in the present study while maternal hypertension was distributed almost in a similar fashion among the cases and controls drawing no significant association. This is comparable with the result of various studies $[25,26]$.

Ray et al found significant association between pregestational diabetes in the mother and congenital heart disease in the newborn[27]. Maternal hyperglycemia in the first trimester is associated with congenital anomaly in the newborn[28]. Farrell et al found that women with poorly controlled diabetes have a 2 to 3 fold increased risk of offspring with all congenital anomalies,including $1 \%$ risk for neural tube defects[29,30]. Jaaz D and Olaafsson and colleagues found a $2.7 \%$ fold increase in congenital malformations in epileptic mothers on antiepileptic drug treatment $[31,32,33]$.

Antenatal complications- History of spotting or bleeding per vaginum, intrauterine growth restriction, oligamnios and hydramnios are all found to be significant factors associated with congenital anomalies in the present study. Rani R, Camero A and Munro have found that significant obstructive renal lesions are associated with a reduction in the amniotic fluid volume in their study $[34,35,36]$. Rddi Rani and Manjula found out an increased incidence of congenital anomalies with an abnormal increase in amniotic fluid volume [37].

Conclusion- The increasing proportion of fetal and infant morbidity due to anomalies have compelled us to study the associations and circumstances they occur.

\section{Original Research Article}

The prevalence of congenital anomalies in the antenatal patients delivering beyond the period of viability in this tertiary care centre was $1.93 \%$. The study definitely helps to know the pattern of congenital anomalies and the relationship of various gestational and familial factors in relation to congenital anomalies.

Considering the high frequency of central nervous system anomalies recorded in this study, it seems to be reasonable to pay more attention to the role of periconceptional folic acid supplementation for the primary prevention of congenital anomalies particularly neural tube defects.

Congenital malformations of the central nervous system like anencephaly, spina bifida, facial defects (cleft lip, cleft palate) can be detected in an early age by ultrasonography, amniocentesis. Various genetic or chromosomal abnormalities can be diagnosed by chorionic villous sampling and maternal serum screening. Certain risk factors can be modified like avoidance of consanguineous marriage, periconceptional folic acid intake, avoidance of teratogens and strict glycemic control in diabetics need to be addressed.

Sonography is a promising tool for the early detection of major malformation during pregnancy to reduce the high morbidity and mortality of the neonates due to congenital malformations. An increasing volume is accumulating on the use of $3 \mathrm{D}$ and $4 \mathrm{D}$ scans and the diagnosis of congenital anomalies could receive revived attention. Present evidence has already suggested that smaller defects such as spina bifida, cleft lip/palate and polydactyly can be more lucidly demonstrated. Other more subtle features such as low set ears, facial dysmorphism or clubbing of feet can be better assessed leading to more effective diagnosis of chromosomal abnormalities. The study of fetal cardiac malformations is also receiving attention. The ability to obtain a good 3D picture is nevertheless still very much dependent on operator skill, the amount of liquor around the fetus, its position and the degree of maternal obesity, so that a good image is not always obtainable.

Thus congenital malformations are emerging as important perinatal problem contributing sizeably to the perinatal morbidity and mortality with considerable repercussion on the mothers and the families affected. The life threatening congenital malformations must be identified by thorough clinical examination because early diagnosis and surgical correction or palliation of these infants offer the best chance for survival.

Funding: Nil, Conflict of interest: Nil Permission from IRB: Yes 


\section{References}

1. Rajangam S, Devi R: Consagunity and chromosomal [1] abnormality in mental retardation and or multiple congenital anomalies. J Anat Soc India. 2007;56:30-33. Glossary of Health Care Terminology. http://whqlibdoc. who.int/ publications/9290201231.pdf.

2. Sadler TW: Langman's Medical Embryology. 10th edition. Lippincott: Williams\& Wilkins; 2011:111.

3. Sachdeva S, Nanda S, Bhalla K, Sachdeva R. Gross congenital malformation at birth in a government hospital. Indian J Public Health. 2014 Jan-Mar;58(1):54-6. doi: 10. 4103 /0019-557X.128170.

4. Penchaszadeh VB. Preventing congenital anomalies in developing countries. Community Genet. 2002;5(1):61-9.

5. Kar A, Preventing Birth Defects in India.

6. Economic and political weekly. 2011; 46 (48). Taksande A, Vilhekar K, Chaturvedi P, Jain $M$. Congenital malformations at birth in Central India: A rural medical college hospital based data. Indian J Hum Genet. 2010; 16: 159-63.

7. Hall J, Solehdin F. Folic acid for the prevention of congenital anomalies. Eur J Pediatr. 1998 Jun; 157 (6): 445-50.

8. Wasserman CR, Shaw GM, O'Malley CD, Tolarova MM, Lammer EJ. Parental cigarette smoking and risk for congenital anomalies of the heart, neural tube, or limb. Teratology. 1996 Apr;53(4):261-7.

9. Hashmi MA. Frequency of consanguinity and its effect on congenital malformation--a hospital based study. J Pak Med Assoc. 1997 Mar;47(3):75-8.

10. Kanaan ZM, Mahfouz R, Tamim H. The prevalence of consanguineous marriages in an underserved area in Lebanon and its association with congenital anomalies. Genet Test. 2008 Sep; 12(3):367-72. doi: 10. 1089/gte. 2007.0093 .

11.Obu et al. Congenital malformations among newborns admitted in the neonatal unit of a tertiary hospital in Enugu, South-East Nigeria - a retrospective study. BMC Research Notes. 2012 5:177.

12. Dutta V, Chaturvedi P. Congenital malformations in rural Maharashtra. Indian Pediatr. 2000 Sep; 37 (9): 998-1001.

\section{Original Research Article}

13. Mohanty C, Mishra OP, Das BK, Bhatia BD, Singh G. Congenital malformation in newborn: A study of 10, 874 consecutive births. J Anat Soc India. 1989; 38:101-11.

14. Studies HUIoP. Turkey Demographic and Health Survey 2003. In: Hacettepe University Institute of Population Studies Mo HGDo Ma CHaFP, State Planning Organization and European Union, editor. Ankara, Turkey 2004. Vrijheid M, Dolk H, Stone D, Abramsky L, Alberman E, Scott J:

15. Socioeconomic inequalities in risk of congenital anomaly. Arch Dis Child2000, 82(5):349-352.

16. Varela MM, Nohr EA, Llopis-González A, Andersen AM, Olsen J. Socio-occupational status and congenital anomalies. Eur J Public Health. 2009 Apr; 19 (2): 161-7. doi: 10.1093/eurpub/ckp003. Epub 2009 Feb 12.

17. Kase JS, Visintainer P. The relationship between congenital malformations and preterm birth. J Perinat Med. 2007; 35(6):538-42.

18. Mili F, Edmonds LD, Khoury MJ, McClearn AB. Prevalence of birth defects among low-birth-weight infants. A population study. Am J Dis Child. 1991 Nov; 145 (11):1313-8.

19. Kramer H, Trampisch H, Rammos S, Giese A: Birth weight of children withcongenital heart disease. Eur J Pediatr 1990, 149(11):752-757.

20. Hollier LM, Leveno KJ, Kelly MA, MCIntire DD, Cunningham FG. Maternal age and malformations in singleton births. Obstet Gynecol. 2000 Nov; 96 (5 Pt 1): 701-6.

21. Hay S, Barbano H. Independent effects of maternal age and birth order on the incidence of selected congenital malformations. Teratology. 1972 Dec;6(3):271-9.

22. Croen LA, Shaw GM. Young maternal age and congenital malformations: a population-based study. Am J Public Health. 1995 May; 85(5):710-3.

23. Grazi RV, Redheendran R, Mudaliar N, Bannerman RM. Offspring of teenage mothers: congenital malformations, low birth weights and other findings. J Reprod Med. 1982 Feb;27(2):89-96.

24. Cordier S, Bergeret A, Goujard J, Ha MC, Aymé S, Bianchi F, Calzolari E, De Walle HE, Knill-Jones R, 


\section{Original Research Article}

Candela S, Dale I, Dananché B, de Vigan C, Fevotte J, Kiel G, Mandereau L. Congenital malformation and maternal occupational exposure to glycol ethers. Occupational Exposure and Congenital Malformations Working Group. Epidemiology. 1997 Jul; 8 (4):355-63.

25. Mathur BC, Karan S, Vijaya Devi KK. Congenital malformations in the newborn. Indian Pediatr. 1975 Feb;12(2):179-83.

26. Madi SA, Al-Naggar RL, Al-Awadi SA, Bastaki LA. Profile of major congenital malformations in neonates in Al-Jahra region of Kuwait. East Mediterr Health J. 2005 Jul; 11(4):700-6.

27. Ordóñez MP, Nazer J, Aguila A, Cifuentes L. Congenital malformations and chronic diseases of the mother. Latin American collaborative study of congenital malformations (ECLAMC) 1971-1999. Rev Med Chil. $2003 ; 131: 404-11$.

28. New Delhi: Reproductive health; Annual report 200203. Indian Council of Medical Research; p. 91.

29. Macintosh MC, Fleming KM, Bailey JA, Doyle P, Modder J, Acolet D, Golightly S, Miller A. Perinatal mortality and congenital anomalies in babies of women with type 1 or type 2 diabetes in England, Wales, and Northern Ireland: population based study. BMJ. 2006 Jul 22; 333 (7560):177. Epub 2006 Jun 16.

30. Schaefer-Graf UM, Buchanan TA, Xiang A, Songster G, Montoro M, Kjos SL. Patterns of congenital anomalies and relationship to initial maternal fasting glucose levels in pregnancies complicated by type 2 and gestational diabetes. Am J Obstet Gynecol. 2000 Feb;182(2):313-20.

31. Wilcox AJ. Birth weight and perinatal mortality: the effect of maternal smoking. Am J Epidemiol. 1993 May $15 ; 137(10): 1098-104$.

32. Kleinman JC, Madans JH. The effects of maternal smoking, physical stature, and educational attainment on the incidence of low birth weight. Am J Epidemiol. 1985 Jun; 121(6):843-55.

33. Horta BL, Victora CG, Menezes AM, Halpern R, Barros FC. Low birthweight, preterm births and intrauterine growth retardation in relation to maternal smoking. Paediatr Perinat Epidemiol. 1997 Apr; 11 (2):140-51.

34. Uchida IA, Holunga R, Lawler C. Maternal radiation and chromosomal aberrations. Lancet. 1968 Nov 16;2 (7577):1045-9.

35. Rittler M, Liascovich R, López-Camelo J, Castilla EE. Parental consanguinity in specific types of congenital anomalies. Am J Med Genet. 2001 Jul 22;102(1):36-43.

36. Becker SM, Al Halees Z, Molina C, Paterson RM. Consanguinity and congenital heart disease in Saudi Arabia. Am J Med Genet. 2001 Feb 15;99(1):8-13.

37. Honein MA, Paulozzi LJ, Moore CA. Family history, maternal smoking, and clubfoot: an indication of a geneenvironment interaction. Am J Epidemiol. 2000 Oct 1;152(7):658-65.

\section{How to cite this article?}

Prema N, Sudhakaran R, Divya. B.V, Meerabai V, Maharani. Prevalence and associated factors of congenital anomalies in a tertiary care centre in Tamilnadu. Obs Rev:J obstet Gynecol 2016;2(4):55-63.doi: 10.17511/joog.2016.i04.03. 